\title{
Odor compounds in cheese made from the milk of cows supplemented with extruded linseed and $\alpha$-tocopherol
}

\author{
F. Sympoura, ${ }^{*}$ A. Cornu, ${ }^{*} \dagger^{1}$ P. Tournayre, ${ }^{*}$ T. Massouras, $\ddagger$ J. L. Berdagué, ${ }^{*}$ and B. Martin $\dagger$ \\ *UR370 Qualité des Produits Animaux, and \\ †UR1213 Herbivores, Institut National de la Recherche Agronomique, Theix, F63122 Saint-Genès Champanelle, France \\ fLaboratory of Dairy Research, Agricultural University of Athens, Athens, Greece
}

\section{ABSTRACT}

Three diets for cows were used to evaluate the effect of extruded linseed (EL) or extruded linseed plus $\alpha$-tocopherol (ELVE) supplementation of a maize silage diet (CO) on the odor-active compounds of SaintNectaire cheese. Cheese odor and flavor profiles were studied by sensory analysis. The volatile compounds were extracted by purge and trap and separated by gas chromatography. The odor compounds were detected and identified using an 8-way olfactometric device and a mass spectrometer. Twenty-nine volatile compounds were considered as contributing to the odor of SaintNectaire cheese. Half the compounds identified were known to be lipid degradation products but not all of them were affected by the diet. Among the markers of unsaturated fatty acid degradation, hexanal was not affected, whereas heptanal was increased more by the ELVE diet ( 6 times) than by the EL (3 times) diet. The ELVE diet led to cheeses with butanoic acid and heptanal odor peaks that were, respectively, 2 and 6 times higher than with the $\mathrm{CO}$ diet, which explained the lower milk odor and flavor scores obtained by sensory analysis on ELVE cheese. Although the cheese-making date had a greater effect than the diet on the aromatic profiles of the cheese, principal component analysis showed that the differences between cheeses obtained on the 3 diets were repeatable. The EL diet successfully enhanced cheese nutritional value without noticeably changing its flavor. $\alpha$-Tocopherol supplementation was found to be unnecessary, as no oxidized odor was found.

Key words: $\alpha$-tocopherol, linseed, cheese odor compound, supplemented diet

\section{INTRODUCTION}

In the diet of Western populations, milk and dairy products are a major source of dietary lipids, especially

Received October 10, 2008.

Accepted February 17, 2009.

${ }^{1}$ Corresponding author: agnes.cornu@clermont.inra.fr saturated lipids, which are strongly implicated in the rise of coronary heart disease (Kromhout et al., 2002) and cancer but also contain essential nutriments beneficial to human health (Parodi, 1997). Over the last 25 yr, consumer demand for dietary unsaturated fatty acid (UFA) associated with healthy diets has been a major force toward changing the fatty acid (FA) profile of milk fat. The key objective is to reduce saturated fatty acid concentration and to increase monounsaturated and polyunsaturated fatty acid concentrations in milk, especially enhancing the content of some unsaturated fatty acids such as n-3 FA and conjugated linoleic acid (CLA).

Conjugated linoleic acid and n-3 FA contents in milk and in dairy products are influenced by the type of diet offered to the cows. Content of CLA and n-3 FA are higher when cows are fed on pasture compared with concentrates or preserved forages, and when cows are grazed on highland pastures compared with lowland pastures (Collomb et al., 2002; Leiber et al., 2005). Milk CLA and n-3 FA levels may also be increased by supplementing cows with vegetable seed or oils rich in UFA (Chilliard and Ferlay, 2004; Collomb et al., 2004). Linseed is one of the vegetable fat sources with the highest amount of C18:3n-3 (50\% of the total FA). Feeding cows with extruded linseed increases milk UFA content and in particular n-3 FA, trans-11 C18:1 FA, and total CLA concentrations, and reduces the n- 6 to n-3 fatty acid ratio (Fuentes et al., 2008). Milk fat is of prime importance in the genesis of cheese sensorial properties, because cheese texture and flavor largely rely on fatty acids and their degradation products. However, extensive trials on the modification of fat composition indicate that increasing the concentration of UFA promotes undesirable processes of lipolysis and oxidation, leading to degradation of fat and unacceptable changes in the color and flavor of milk and dairy products (Campbell et al., 2003). Although it is well known that a great number of cheese aroma compounds originate from lipid degradation, very few studies have focused on the consequences of lipid supplements on cheese sensorial properties, and to our knowledge this is 
the first study dealing with extruded linseed. Texture is invariably the most affected by lipid supplementation, unsaturated fatty acid-enriched cheese being less firm, less friable, and more melting. Flavor may or may not be affected, depending on the cheese variety and probably also on the basal diet of the cows: concentraterich diets more readily lead to flavor defects than does pasture. Unsaturated fatty acids may be oxidized and induce undesirable oxidized and rancid flavors. Allred et al. (2006) supplemented cows fed a control hay plus concentrate diet with calcium salts of palm and fish oil alone, or with $5 \%$ extruded soybean or $0.75 \%$ soybean oil. They observed a decrease in the acceptability of Cheddar cheese made from the supplemented cows' milk and the appearance between 30 and $90 \mathrm{~d}$ ripening of oily, oxidized, rancid, and sulfide off-flavors, which disappeared or were less marked after $180 \mathrm{~d}$ of ripening. In contrast, extruded soybeans distributed to grazing cows did not modify the sensory properties of the resulting Cheddar (Khanal et al., 2005). Likewise, a mixture of sunflower and fish oil (4.5\% of the diet) did not induce off-flavor in Caerphilly cheese (Jones et al., 2005) nor did a soybean oil supplement in Edam (Ryhanen et al., 2005). These last authors, however, reported slightly slower ripening of the cheese resulting from the supplemented diets.

Because modifying milk lipid composition could result in decreased cheese acceptability due to undesirable oxidation products, antioxidants could help prevent this drawback. Milk fat-soluble vitamins such as $\alpha$-tocopherol (VitE), retinol, and $\beta$-carotene contribute to protect lipids from oxidative degradation. It could therefore be interesting to determine if adding VitE to the linseed dietary supplement could prevent milk and cheese from becoming oxidized. The aim of the present study was to investigate the effects on the volatile odor-active compounds of Saint-Nectaire, a Protected Denomination of Origin cheese originating from $\mathrm{Au}-$ vergne (France), of supplementing a control diet with extruded linseed alone or with extruded linseed plus $\alpha$-tocopherol.

\section{MATERIALS AND METHODS}

\section{Experimental Design}

Eighteen Holstein $(\mathrm{n}=9)$ and Montbéliarde ( $\mathrm{n}=$ 9) cows were divided in 3 equal groups of 6 cows (3 Holstein and 3 Montbéliarde). The trial began on January 29, 2007. During a first 3-wk period all groups were fed the same diet based on hay and corn silage with a concentrate mixture (cereals and soybean meal). Then, for a 5-wk period, group 1 (CO; control) was fed a corn silage diet, group 2 (EL; extruded linseed) was fed a corn silage diet supplemented with $3.4 \mathrm{~kg}$ of extruded linseed substituted for $3.6 \mathrm{~kg}$ of concentrates. This diet was calculated so that the added fat from extruded linseed represented $5 \%$ of the DMI. Group 3 (ELVE; EL plus VitE) was fed the same diet as group 2 but supplemented with 7,500 IU of VitE per cow and per day. Throughout the entire experiment, the cows were given $200 \mathrm{~g} / \mathrm{d}$ per cow of a mineral and vitamin additive (phosphorus $5 \mathrm{~g} / \mathrm{kg}$, calcium $20 \mathrm{~g} / \mathrm{kg}$, magnesium 4.5 $\mathrm{g} / \mathrm{kg}$, vitamin A 600,000 IU/ $/ \mathrm{kg}$, and vitamin E 1,500 $\mathrm{IU} / \mathrm{kg})$.

During the last $3 \mathrm{wk}$, the cows were milked twice a day and the milk of each group was collected separately. The milk from the previous evening milking was kept at $4^{\circ} \mathrm{C}$, mixed with the following morning's milking to obtain $40 \mathrm{~L}$ from each group, and transported to the experimental dairy in Aurillac (Cantal, France).

The raw milk obtained from each group was processed into Saint-Nectaire cheese as described previously (Cornu et al., 2005; Verdier-Metz et al., 2005). The average composition of CO, EL, and ELVE mixed milk was, respectively, 34.6, 31.9, and $31.1 \mathrm{~g} / \mathrm{L}$ for protein, $39.8,35.8$, and $35.6 \mathrm{~g} / \mathrm{L}$ for fat, and 66,288 , and $182 \times$ $10^{3}$ cells $/ \mathrm{mL}$ for SCC. Spontaneous lipolysis estimated as FFA net production (Jellema, 1991) during $24 \mathrm{~h}$ of storage at $4^{\circ} \mathrm{C}$ was $1.94,0.91$, and $0.85 \mathrm{mEq} / 100 \mathrm{~g}$ of fat, respectively, in CO, EL, and ELVE mixed milk. Cheeses were made from Co, El, and ELVE milks on 4 dates (March 8, 15, 20, and 22); consequently, a total of 12 cheeses was manufactured, 1 for each of the 3 groups in 4 different days. Cheese was allowed to mature for 8 wk before being cut, wrapped in tinfoil under vacuum in sealed polyethylene bags, and stored at $-20^{\circ} \mathrm{C}$ until analysis. The average CO, EL, and ELVE cheese FA composition was 77,58 , and $60 \mathrm{~g} / 100 \mathrm{~g}$ of fat for saturated FA; 18, 33, and $32 \mathrm{~g} / 100 \mathrm{~g}$ of fat for monounsaturated FA; and 2, 5, and $5 \mathrm{~g} / 100 \mathrm{~g}$ of fat for polyunsaturated FA.

\section{Cheese Sensory Analyses}

Cheese sensory analyses were performed by a panel of 12 trained assessors selected 2 yr ago. The assessors first answered a classified advertisement in a local newspaper and were then selected for their ability to detect and recognize basic tastes and odors. These panelists were trained to improve their skills with both diluted pure compounds and cheese. The panelists also had 2 training sessions with the cheeses made in this experiment. During the experimental sessions, panelists gave scores of between 0 and 7 for the intensity of 32 attributes -11 for odor and 6 for flavor. The other attributes related to body, texture, color, and appearance. During one session, 3 cheeses (CO, EL, ELVE) 
Table 1. Distribution of vocabulary items used by the 8 panelists in the 9 olfactory classes defined for this purpose

\begin{tabular}{ll}
\hline Olfactory class & Vocabulary items \\
\hline Lactic-cheesy & Butter, dirty socks, cream, Emmental, fermented, feet, cheese, vomit, milk, Gruyere, Roquefort, yogurt \\
Fruity-floral & Citrus fruit, pineapple, banana, grapefruit, strawberry, fruit candy, melon, cherry, lemon, floral, fruity, \\
& lilac, orange, apple, pear, green apple, rose, violet \\
Acid-alcohol & Acid, alcohol, ethanol, sour, vinegar \\
Earthy-undergrowth & Mushrooms, earth, forest, moss, wood, pine, sawdust \\
Vegetable-green & Artichoke, carrot, celery, chlorophyll, cabbage, potatoes, hay, grass, onion, vegetable, beans, ivy \\
Chemical-plastic & Acetone, ammoniac, chemical, chlorine, sulfur odor, formaldehyde, chemical gas, metallic, plastic, \\
& rubber, naphthalene, glue \\
Empyreumatic & Almond, burnt, peanuts, cocoa, chocolate, coffee, caramel, ash, wood fire, smoke, roasted, hazel, peppermint, \\
Animal & hot bread, pepper, biscuit \\
Not classified & Dung, fish, salmon, sardine, urea, perspiration, eggs, leather, dog \\
& $\begin{array}{c}\text { Dust, stone, disagreeable, sugar, baby, hot, cooking, unknown, sweet, chewing gum, shampoo, perfume, } \\
\text { paper, fresh, honey, medicament, cement, face cream, musty, piquant, detergent }\end{array}$ \\
\hline
\end{tabular}

made on the same day were coded with 3-digit random numbers and presented at $20^{\circ} \mathrm{C}$ to the panelists in varying order using a monadic sequential method. Four sessions were necessary to analyze the 4 cheese-making dates separately.

\section{GC-Olfactometry and GC-Olfactometry-MS Analysis}

Volatile compounds were extracted by purge and trap and independently analyzed using both the 8-way GColfactometry (GC-O) device (8W-GC-O) described by Tournayre and Berdagué (2005) and a GC-O-MS device. The $8 \mathrm{~W}-\mathrm{GC}-\mathrm{O}$ method maximizes the number of odorous peaks detected from a sample, by allowing a panel of 8 sniffers to detect the same chromatography run. No instrumental detection was performed. The GCO-MS procedure aims to identify, without ambiguity, the compounds responsible for odors. In this case, detection was carried out simultaneously by a mass spectrometer and by a single sniffer selected for his abilities, allowing olfactograms to be aligned with mass chromatograms. The samples were allowed to thaw at room temperature before being unpacked. The interactions between diet and date of manufacture were nonsignificant for most of the sensory descriptors; therefore, we chose to perform the analyses on a blend of the cheeses made on March 8 and 15, and on a blend of the cheeses made on March 20 and 22 to reduce the number of analyses to 6 runs of the $8 \mathrm{~W}-\mathrm{GC}-\mathrm{O}$. One gram was cut from each of the 2 cheeses and rapidly homogenized with $8 \mathrm{~g}$ of anhydrous sodium sulfate $\left(\mathrm{Na}_{2} \mathrm{SO}_{4}\right)$ in a mortar. Three grams of the powdery mixture was placed on a $0.2-\mathrm{g}$ glass wool bed in a cylindrical glass extraction cartridge $(28 \mathrm{~mm}$ diameter $\times 47 \mathrm{~mm}$ height; Etablissements Maillières Frères, Aubière, France). To compensate for the loss of the most volatile compounds, 2 cartridges containing samplings of the same cheeses were successively used during one analysis. Dynamic headspace extraction was performed using a Tekmar apparatus (TekmarDohrmann, Cincinnati, $\mathrm{OH}$ ) as follows: purge for 45 min with the first cartridge followed by 15 min with the second cartridge, by a $60 \mathrm{~mL} / \mathrm{min} 99.995 \%$ helium flow. Extracted volatile compounds were concentrated on a $180 \mathrm{~mm} \times 6.35 \mathrm{~mm}$ i.d. trap packed with Tenax TA 6080 Mesh (Supelco, Bellefonte, PA) at $30^{\circ} \mathrm{C}$. A dry purge was applied for 3 min with $60 \mathrm{~mL} / \mathrm{min} 99.995 \%$ helium before desorption for $10 \mathrm{~min}$ at $215^{\circ} \mathrm{C}$ using $99.9995 \%$ helium, cryofocusing at $-150^{\circ} \mathrm{C}$ with liquid nitrogen in the chromatograph injection port and injection by heating $2 \mathrm{~min}$ at $215^{\circ} \mathrm{C}$. The chromatograph (Hewlett Packard 4890D, Agilent Technologies, Palo Alto, CA) was coupled to a divider that distributed the volatile component outflow synchronously to 8 transfer lines connected to sniffing ports located in separate booths. The separation was performed in an RTX-5 capillary column $(60 \mathrm{~m} \times 0.53 \mathrm{~mm}$ i.d. $\times 1.5 \mu \mathrm{m}$, Restek, Evry, France) with a $99.995 \%$ helium flow rate of $8 \mathrm{~mL} / \mathrm{min}$. The oven temperature was programmed as follows: 5 min isothermal at $40^{\circ} \mathrm{C}, 4^{\circ} \mathrm{C} / \mathrm{min}$ increase to $215^{\circ} \mathrm{C}$, hold for $28 \mathrm{~min}$. At the sniffing ports, 8 panelists indicated the beginning, the end, the intensity from 1 to 5 , and the description of each odor they perceived from 0 to $35 \mathrm{~min}$.

The GC-O-MS device comprised a chromatograph (GC 6890, Agilent Technologies), a mass selective detector (MSD 5973 Inert, Agilent Technologies), and a single sniffing port. The extraction conditions were as follows: purge at $20^{\circ} \mathrm{C}$ with $30 \mathrm{~mL} / \mathrm{min} 99.995 \%$ helium, $45 \mathrm{~min}$ in a first cartridge and then $15 \mathrm{~min}$ in a second cartridge as above, trap on Tenax at $30^{\circ} \mathrm{C}$, dry purge for $3 \mathrm{~min}$ with $30 \mathrm{~mL} / \mathrm{min} 99.995 \%$ helium, desorption for $10 \mathrm{~min}$ at $220^{\circ} \mathrm{C}$ with $1 \mathrm{~mL} / \mathrm{min} 99.9995 \%$ helium, and injection $2 \mathrm{~min}$ at $220^{\circ} \mathrm{C}$. The chromatography column (Supelco SPB5, $60 \mathrm{~m} \times 0.32 \mathrm{~mm}$ id $\times 1 \mu \mathrm{m}$ ) was maintained at $40^{\circ} \mathrm{C}$ for $5 \mathrm{~min}$, increased by $4^{\circ} \mathrm{C} /$ min to $220^{\circ} \mathrm{C}$, and held for 5 min. The divided column outflow was simultaneously directed toward a mass spectrometer monitoring the $\mathrm{m} / z$ between 15 and 230 during the 45-min period and an olfaction port where a single assessor detected odors between 5 and $35 \mathrm{~min}$. 


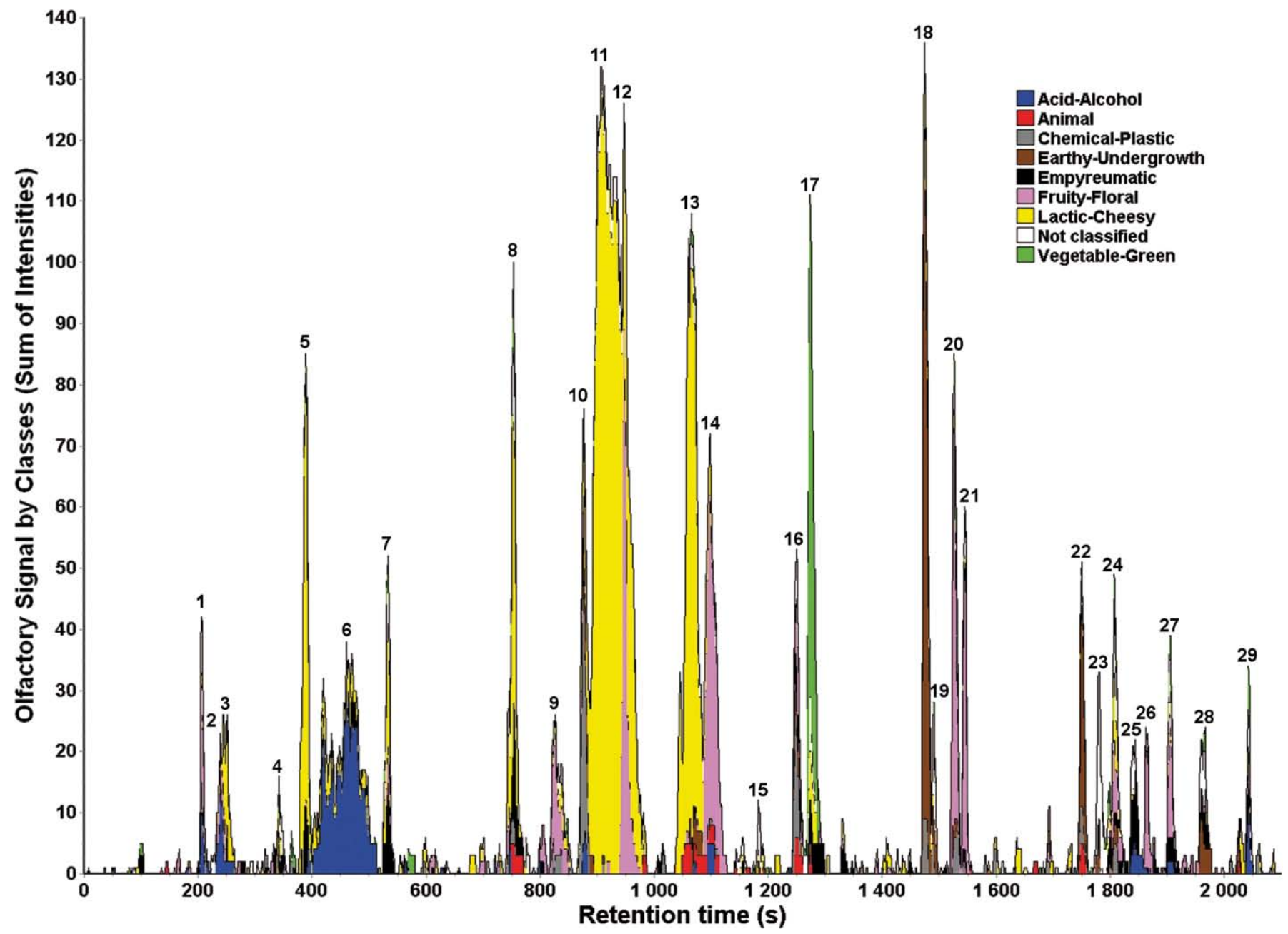

Figure 1. Total olfactory signal by classes. The breakdown of the total olfactory signal into 9 classes clearly shows the olfactogram zones belonging to a given olfactory class. Labels correspond to the peak numbers given in Table 2 .

Identification of all volatile compounds was carried out by comparing their mass spectra and linear retention indices with those in published databases (Kondojoyan and Berdagué, 1996).

\section{Acquisition and Analysis of Olfactometry Data}

Olfactometry data were recorded at a rate of 1 $\mathrm{scan} / \mathrm{s}$ from 0 to $2,100 \mathrm{~s}$ and processed using the Acquisniff software according to the VIDEO-sniff method (Berdagué and Tournayre, 2004). This method allows maximized information recovery from quantitative (detection frequency, intensity, perception duration) as well as qualitative odor description data (Tournayre and Berdagué, 2006). The odor descriptive vocabulary items were distributed into 9 olfactory classes as described in Table 1.

The GC-O data from the multi-port system were synchronized with those from the single-port GC-O-
MS by using well-characterized odor signals as internal standards. Because alkanes are odorless, retention indices were calculated using the straight-chain aldehydes naturally occurring in the samples (e.g., hexanal, heptanal, octanal, nonanal). Odor active compounds were identified by comparing their descriptors, mass spectra, and relative retention indices to published databases (Wiley, 1995; Kondojoyan and Berdagué, 1996; NIST/ EPA/NIH, 1996; Acree and Arn, 2004) and to those of authentic standards. Pure compounds were obtained from Fluka (Saint-Quentin Fallavier, France) for 2-methyl-propanoic acid and 3-methyl-butanoic acid; from Carlo Erba (Val de Reuil, France) for acetic acid; and from Aldrich (Saint-Quentin Fallavier, France) for ethyl alcohol, 2-propanone, 2,3-butanedione, 3-methylbutanal, 2-methyl-propanoic acid ethyl ester, toluene, butanoic acid, hexanal, 2-methyl-butanoic acid, styrene, heptanal, 3-(methylthio)-propanal, 1-octen-3-ol, 6-methyl-5-hepten-2-one, 2-octanone, hexanoic acid 
Table 2. Identification of the compounds responsible for the main odorous peaks and most representative descriptors given by the judges

\begin{tabular}{|c|c|c|c|c|}
\hline Peak number ${ }^{1}$ & Main odors given by the panelists & $\mathrm{RI}^{2}$ & $\mathrm{ID}^{3}$ & Chemical name \\
\hline 2 & Acetone & 500 & $\mathrm{~A}$ & 2-Propanone \\
\hline 3 & Lactic-cheesy & 509 & $\mathrm{C}$ & 2-Propanol \\
\hline 5 & Butter & 586 & $\mathrm{~A}$ & 2,3 -Butanedione \\
\hline 6 & Vinegar & 628 & $\mathrm{~A}$ & Acetic acid \\
\hline 7 & Cheesy-chocolate & 683 & $\mathrm{~A}$ & 3-Methyl-butanal \\
\hline 11 & Vomit-cheesy-feet & 793 & A & Butanoic acid \\
\hline 12 & Green apple & 799 & $\mathrm{~A}$ & Hexanal \\
\hline 13 & Cheesy & 851 & A & 3-Methyl-butanoic acid \\
\hline 14 & Fruity & 854 & $\mathrm{~A}$ & 2-Methyl-butanoic acid \\
\hline 15 & Rubber & 896 & $\mathrm{~A}$ & Styrene \\
\hline 16 & Fruity & 900 & $\mathrm{~A}$ & Heptanal \\
\hline 22 & Mushroom & 1,080 & $\mathrm{C}$ & 1-Nonen-3-ol \\
\hline 23 & Mushroom & 1,087 & $\mathrm{~A}$ & 2-Nonanone \\
\hline 24 & Citrus & 1,100 & $\mathrm{C}$ & Nonanal \\
\hline 25 & Indeterminate & & & Not identified \\
\hline 26 & Rose floral & 1,118 & A & Phenylethyl alcohol \\
\hline 27 & Fruity-floral & 1,127 & $\mathrm{~A}$ & Formic acid octyl ester \\
\hline 28 & Woody & 1,147 & $\mathrm{~B}$ & 2-Nonenal \\
\hline 29 & Indeterminate & & & Not identified \\
\hline
\end{tabular}

${ }^{1}$ Peak number as shown in Figure 1.

${ }^{2}$ Experimental retention indices (RI) calculated from the DB5 capillary column of the GC/MS system.

${ }^{3}$ Reliability of the identification: $\mathrm{A}=\mathrm{RI}+\mathrm{MS}+$ odor description in accordance with those of standards; $\mathrm{B}=\mathrm{RI}+\mathrm{MS}+$ odor description in accordance with those of databases; $\mathrm{C}=$ peak not found in MS or several candidate molecules or data missing in databases.

ethyl ester, octanal, 2-nonanone, nonanal, phenylethyl alcohol, and formic acid octyl ester.

\section{Statistical Analyses}

Statistical analyses were performed using Statistica software (Statsoft, Maisons-Alfort, France). The GC-O peak areas obtained by summing the individual olfactory signals over the peak duration were submitted to an ANOVA according to the model

$$
\mathrm{X}_{\mathrm{ijr}}=\mu+\operatorname{Diet}_{\mathrm{i}=3}+\text { Assessor }_{\mathrm{j}=8}+\varepsilon_{\mathrm{ijr}=2},
$$

where $\mathrm{X}=$ variable studied (peak no. $\mathrm{x}$ ) $; \mu=$ mean effect; Diet $=$ diet effect with $\mathrm{i}=3$ levels; Assessor $=$ assessor effect with $\mathrm{j}=8$ levels; and $\varepsilon=$ residual error with $\mathrm{r}=2$ replicates. Sensory analysis scores were submitted to an ANOVA to study the effects of the cows' diet, cheese-making date, and their interaction according to the model

$$
\begin{gathered}
\mathrm{X}_{\mathrm{i}}=\mu+\text { Diet }_{\mathrm{i}=3}+\text { Assessor }_{\mathrm{j}=12}+\text { Date }_{\mathrm{k}=4} \\
+ \text { Diet }
\end{gathered}
$$

where $\mathrm{X}=$ variable studied (score of the attribute $\mathrm{x}$ ); $\mu=$ mean effect; Diet $=$ diet effect with $\mathrm{i}=3$ levels; Assessor $=$ assessor effect with $\mathrm{j}=12$ levels; Date $=$ cheese-making date effect with $\mathrm{k}=4$ levels; and $\varepsilon=$ residual error with $\mathrm{r}=1$ replicate. Principal component analysis (PCA) was performed using the mean data for cheese-making dates (March 8 and 15 and March 20 and 22). Sensory analysis descriptors (mean scores for the 12 judges and 2 cheese repetitions) significantly affected by the cows' diet (or by the interaction between diet and cheese-making date) were active variables, and the odor compounds (mean areas over the 8 judges) significantly affected by the cows' diet were supplementary variables.

\section{RESULTS AND DISCUSSION}

\section{Odor Compound Identification}

Summing up the intensities of the odors detected by the 8 panelists on the 6 cheeses in the total olfactogram shown in Figure 1 resulted in a great amount of vocabulary per peak, which helped identify the molecules responsible for odors. Twenty-seven of the compounds 
Table 3. Mean odorous peak areas (intensity $\times$ duration) from GC-olfactometry analysis of cheese from the milk of cows fed on hay plus concentrate alone (CO), supplemented with extruded linseed (EL), or with EL plus vitamin E (ELVE)

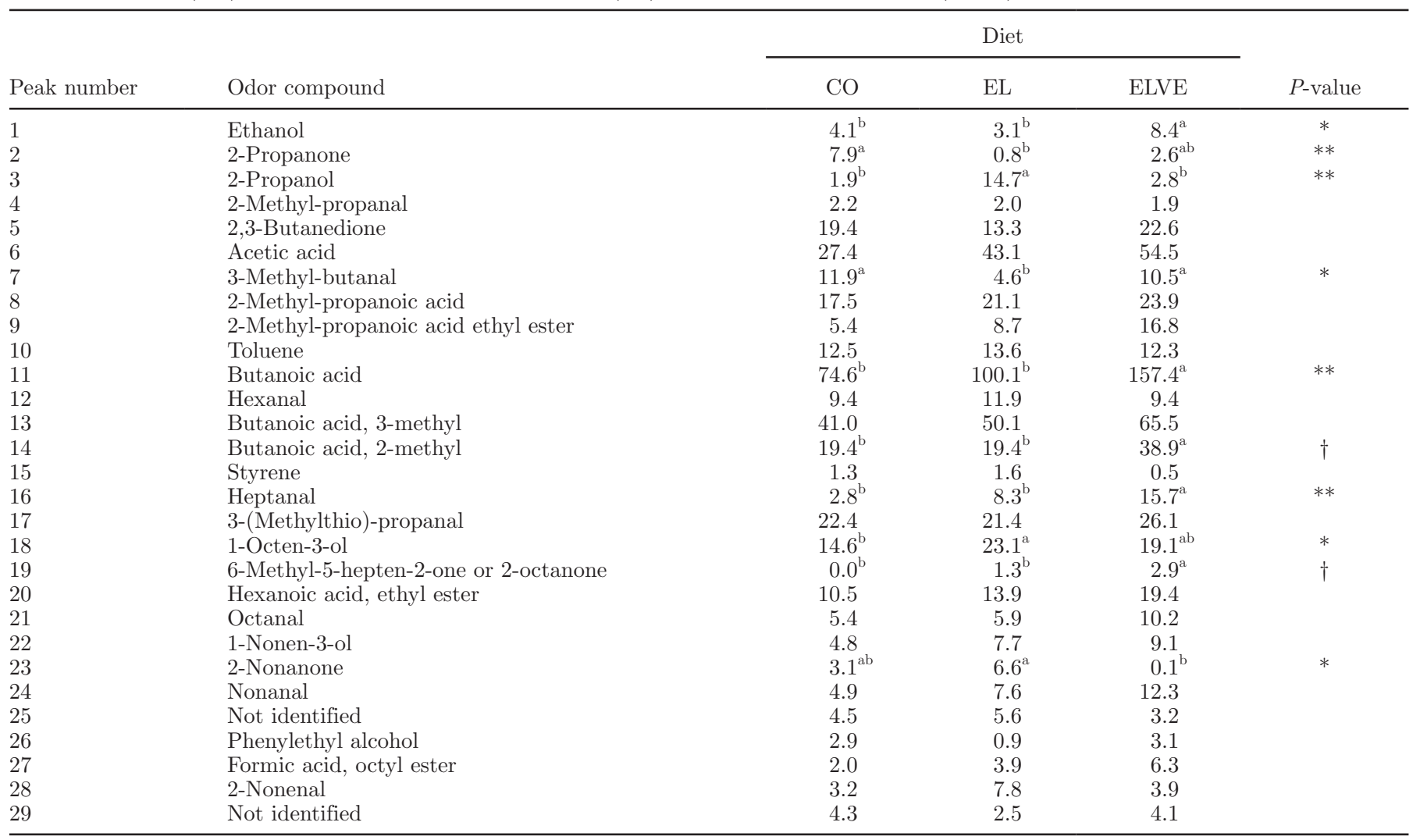

${ }^{\mathrm{a}, \mathrm{b}}$ Means within a row with different superscripts differ significantly.

$\dagger P<0.1{ }^{*} P<0.05 ;{ }^{*} P<0.01$ : effect of the cows' diet on the total olfactive signal.

responsible for the 29 peaks were identified with varying reliability: 5 fatty acids, 3 esters, 4 ketones, 8 aldehydes, 5 alcohols, and 2 miscellaneous compounds were found (Table 2). All of these compounds have previously been identified at different ratios in Salers cheese (Berdagué et al., 2007).

The most abundant odors for Saint-Nectaire cheese were of the lactic and the fruity classes, as described in Table 1. The information given by Figure 1 and Table 2 shows that volatile compounds contributing to the lactic odor were 2-propanol (peak 3), 2,3-butanedione (peak 5), isobutanoic acid (peak 8), butanoic acid (peak 11), and 3-methyl-butanoic acid (peak 13). The volatile compounds contributing to the fruity odor were the esters 2-methyl-propanoic acid ethyl ester (peak 9), hexanoic acid ethyl ester (peak 20), and formic acid octyl ester (peak 27); the aldehydes hexanal (peak 12), heptanal (peak 16), and octanal (peak 21), and possibly ethanol (peak 1), which gives an alcoholic, floral note, phenylethyl alcohol (peak 26), which gives a rose note; and the S-enantiomer of 2-methyl-butanoic acid (peak 14), which gives a fruity note (Leffingwell, 2002).
In the last part of the olfactogram, many odors remained unidentified or were identified with a low reliability (Table 2). These difficulties were because this part of the olfactogram was very crowded, the description of the panelists was inadequate, and there were many candidate molecules in the corresponding area in the mass chromatograms.

\section{Effect of Diet on the Odor Compounds}

Nine odor compounds were significantly affected by the cows' diet (Table 3). Ethanol, butanoic acid, 2-methylbutanoic acid, and heptanal peak areas were equivalent in $\mathrm{CO}$ and $\mathrm{EL}$ cheese and much higher in ELVE cheese. The amounts of 2-propanone and 3-methylbutanal were lower in EL than in CO cheese; these compounds in ELVE being, respectively, intermediate and equivalent to that in CO. Inversely, the amounts of 1-octen-3-ol and 2-propanol were higher in EL than in CO cheese; these compounds in ELVE being, respectively, intermediate and equivalent to that in CO. 2-Nonanone was higher in EL than in ELVE 
Table 4. Sensorial analysis: cheese flavor and odor descriptor scores for the 4 cheese-making dates

\begin{tabular}{|c|c|c|c|c|c|c|}
\hline \multirow[b]{2}{*}{ Item } & \multirow[b]{2}{*}{$\mathrm{CO}$} & \multirow[b]{2}{*}{ EL } & \multirow[b]{2}{*}{ ELVE } & \multicolumn{3}{|c|}{ Effect $^{1}$} \\
\hline & & & & Diet & Date & Diet $\times$ Date \\
\hline \multicolumn{7}{|l|}{ Flavor } \\
\hline Intensity & 4.25 & 4.33 & 4.27 & \multirow{6}{*}{$* * *$} & $* * *$ & \multirow[t]{6}{*}{$\dagger$} \\
\hline Mushroom & 1.00 & 0.90 & 0.83 & & $* *$ & \\
\hline Dried fruit & 1.08 & 1.54 & 1.42 & & & \\
\hline Milk & $4.33^{\mathrm{a}}$ & $2.73^{\mathrm{b}}$ & $2.71^{\mathrm{b}}$ & & & \\
\hline Fish & 0.04 & 0.04 & 0.04 & & & \\
\hline Plant & 1.71 & 1.83 & 1.65 & & $*$ & \\
\hline \multicolumn{7}{|l|}{ Odor } \\
\hline Intensity & 4.67 & 4.50 & 4.46 & & $* * *$ & \multirow{11}{*}{$* *$} \\
\hline Straw & 1.15 & 1.33 & 1.38 & \multirow{10}{*}{$* *$} & & \\
\hline Mushroom & 1.13 & 0.96 & 1.15 & & $* *$ & \\
\hline Silage & 0.88 & 0.67 & 0.65 & & $* * *$ & \\
\hline Cowshed & 1.27 & 1.21 & 1.60 & & $* * *$ & \\
\hline Dried fruit & 1.21 & 1.13 & 0.98 & & & \\
\hline Milk & $3.75^{\mathrm{a}}$ & $2.67^{\mathrm{b}}$ & $2.63^{\mathrm{b}}$ & & $* *$ & \\
\hline Musty & 0.75 & 0.75 & 1.13 & & $* * *$ & \\
\hline Pungent & 1.10 & 1.21 & 1.17 & & $* * *$ & \\
\hline Fish & 0.08 & 0.35 & 0.08 & & $*$ & \\
\hline Rancid & 0.83 & 0.81 & 0.90 & & $* *$ & \\
\hline
\end{tabular}

cheese, with $\mathrm{CO}$ being intermediate. Hexanal, heptanal, 1-octen-3-ol, octanal, 1-nonen-3-ol, and nonanal are known to originate from the degradation of milk unsaturated fatty acids (McSweeney and Sousa, 2000). Of these, EL supplementation only increased 1-octen3-ol. In contrast, the ELVE diet did increase heptanal. Therefore, the vitamin $\mathrm{E}$ ingested by the cows did not protect cheese lipid against oxidation, but in some cases seems to have intensified this oxidation, as if having been oxidized itself.

Seven branched compounds were found in this study: 2-methyl-propanal, 2-methyl-propanoic acid, and 2-methyl-propanoic acid ethyl ester did not vary within the diets; 3-methyl-butanal was lower in EL than in both CO and ELVE; and 3-methyl-butanoic acid gradually increased from $\mathrm{CO}$ to EL to ELVE. These branchedchain acids and aldehydes probably originate from the degradation of branched-chain amino acids (McSweeney and Sousa, 2000). Although no evidence can be found in the literature, branched-chain acids and aldehydes might also result from the additional protease activity caused by the somatic cells in the EL and ELVE milks. The increase of 2-methyl-butanoic acid and of the peak 19 tentatively identified as 6-methyl-5-hepten-2-one in the ELVE cheese raises the question of whether these compounds might directly originate from vitamin $\mathrm{E}$ degradation. Indeed, in this experiment, the vitamin E content in ELVE milk was more than 2-fold higher than that in the $\mathrm{CO}$ and EL milk (B. Graulet, INRA, Theix, France; personal communication). No literature was found, however, to support this hypothesis.

\section{Cheese Sensorial Analysis}

Cheese sensorial analysis revealed strong effects of the cheese-making date but little effect of the cows' diet on the flavor and odor components (Table 4), although significant texture changes were found (data not shown). Lipid supplementation decreased the "milk" note of the cheese flavor as well as odor. In addition, interactions between the cheese-making date and the cows' diet were observed for the intensities of the cheese flavor and odor, and for the "fish" note of the odor. In fact, this fish odor was detected in one of the EL cheeses only (made on March 22) and at a low intensity (mean score 1.42/7), and it can be said that no offflavor was caused by the lipid supplement. The ELVE cheeses received odor and flavor scores equivalent to those of EL cheeses.

In the PCA shown in Figure 2a, the cheeses are separated according to their cheese-making date along the first axis, which explains $61.5 \%$ of the variability in cheese sensorial characteristics. The cheeses obtained from the milk of supplemented cows are separated from the $\mathrm{CO}$ cheeses along the second axis, which explains about $26 \%$ of the variability. Adding vitamin $\mathrm{E}$ to the 
a
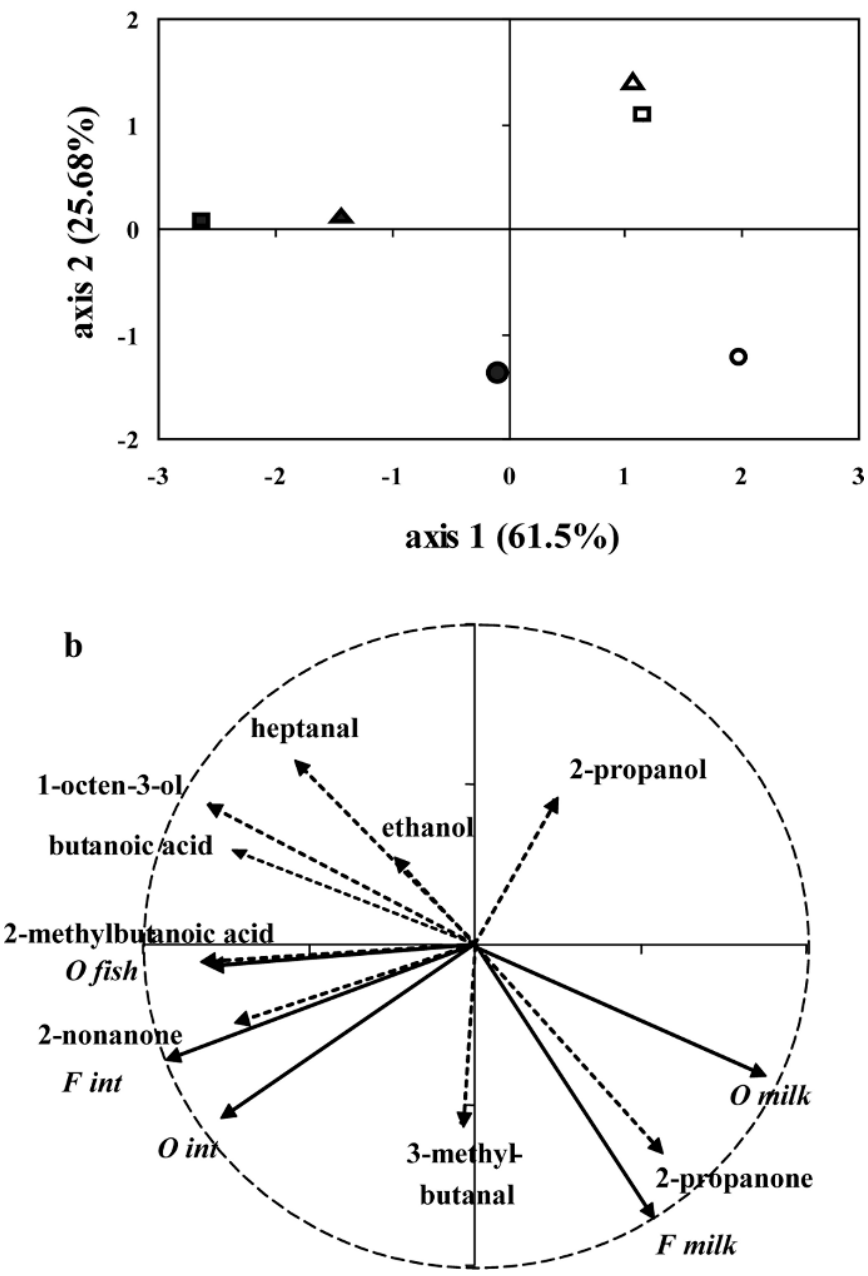

Figure 2. Principal component analysis of the sensory attributes and GC-olfactometry data of the 6 cheeses. a) Sample plot: circles $=$ $\mathrm{CO}$ cheeses (control diet), squares $=\mathrm{EL}$ cheeses (diet supplemented with extruded linseed), and triangles = ELVE cheeses (diet supplemented with extruded linseed and vitamin E); open symbols = cheeses made on March 8 and 15; solid symbols = cheeses made on March 20 and 22 . b) Variable plot: solid lines = sensory attributes as active variables; dotted lines $=$ GC-olfactometry data as additional variables.

lipid supplement had little or no effect. The representation of the variables on the same plane (Figure 2b) shows that the cheeses made on March 20 and 22 were essentially characterized by their higher odor and flavor intensity ( $O \_$int and $F \_$int) compared with those made on March 8 and 15. This effect of cheese-making date probably reflects the variability of the raw milk microbial ecosystem, which is further amplified by differential development during cheese ripening, resulting in the acknowledged high diversity of raw-milk cheese (Duthoit et al., 2005). The cheeses made from the milk of supplemented cows are separated from the control cheeses along a bisecting line opposing milk flavor and milk odor (F_milk, O_milk) to butanoic acid. Rather than increasing the overall intensity of cheese flavor, butanoic acid, which is a descriptor for strong cheese, exerts a masking effect on milk odor, a soft cheese descriptor. Trimethylamine, the compound usually responsible for fish odor (O_fish) in cheese, was not found by GC-O, whereas 2-nonanone correlated well with this odor on the PCA (Figure 2b). In fish, the fishy odor is mainly due to a combination of aldehydes, alcohols, and ketones (including 2-nonanone) resulting from the sequential actions of lipoxygenase and hydroperoxide lyase on PUFA (Shen et al., 2007). Therefore, it is possible that in cheese, a slight change in the proportions of these different families results in the production of a fishy odor.

\section{CONCLUSIONS}

Supplementing cows with extruded linseeds is an efficient way to improve milk fat nutritional quality. However, consumers demand healthier products but with unchanged aromatic properties. In our study, when comparing cheese from the extruded linseed-supplemented diet (EL) to the control, only 4 odor-active compounds were significantly $(P<0.05)$ influenced by the addition of extruded linseed in the cows' diet, 2 of which (2-propanone and 3-methyl-butanal) decreased and 2 of which (2-propanol and 1-octen-3-ol) increased. On the other hand, the major odor compounds [ethanol, butanoic acid, hexanal, methylbutanoic acids, 3-(methylthio)-propanal and octanal] were little affected. Moreover, no fishy off-flavor or rancid note was detected by sensory analysis. The use of an antioxidant in the ELVE diet increased the intensity of some major odor compounds such as butanoic and methylbutanoic acids, but did not seem to prevent unsaturated fatty acid degradation, because markers such as heptanal were much higher in ELVE than in EL. Nevertheless, sensorial characteristics of EL and ELVE cheeses were similar, indicating that adding vitamin $\mathrm{E}$ in the diet of dairy cows would be a useless additional cost.

\section{ACKNOWLEDGMENTS}

The research was supported by EU project TRUEFOOD "Traditional United Europe Food," under the 6th Framework Program for RTD (contract no. FOODCT-2006-016264) and by a "Leonardo Da Vinci' European fellowship.

\section{REFERENCES}

Acree, T., and A. Arn. 2004. Flavornet and human odor space. http:// www.flavornet.org/ Accessed Jan. 21, 2009.

Allred, S. L., T. R. Dhiman, C. P. Brennand, R. C. Khanal, D. J. McMahon, and N. D. Luchini. 2006. Milk and cheese from cows 
fed calcium salts of palm and fish oil alone or in combination with soybean products. J. Dairy Sci. 89:234-248.

Berdagué, J. L., and P. Tournayre. 2004. The VIDEO-Sniff ${ }^{\circledR}$ method, a new approach for the "Vocabulary-Intensity-Duration" study of "Elementary Odours" perceived by gas chromatography-olfaction. Pages 514-519 in Flavour Research at the Dawn of the TwentyFirst Century. Lavoisier Editions, Cachan, France.

Berdagué, J. L., P. Tournayre, and S. Cambou. 2007. Novel multigas chromatography-olfactometry device and software for the identification of odor-active compounds. J. Chromatogr. A 1146:85-92.

Campbell, W., M. A. Drake, and D. K. Larick. 2003. The impact of fortification on conjugated linoleic acid (CLA) on the quality of fluid milk. J. Dairy Sci. 86:43-51.

Chilliard, Y., and A. Ferlay. 2004. Dietary lipids and forages interactions on cow and goat milk fatty acid composition and sensory properties. Reprod. Nutr. Dev. 44:467-492.

Collomb, M., U. Bütikofer, R. Sieber, B. Jeangros, and J. O. Bosset. 2002. Composition of fatty acids in cow's milk fat produced in the lowlands, mountains and highlands of Switzerland using highresolution gas chromatography. Int. Dairy J. 12:649-659.

Collomb, M., R. Sieber, and U. Bütikofer. 2004. CLA isomers in milk fat from cows fed diets with high levels of unsaturated fatty acids. Lipids 39:355-364.

Cornu, A., N. Kondjoyan, B. Martin, I. Verdier-Metz, P. Pradel, J. L. Berdagué, and J. B. Coulon. 2005. Terpene profiles in Cantal and Saint-Nectaire-type cheese made from raw or pasteurised milk. J. Sci. Food Agric. 85:2040-2046.

Duthoit, F., C. Callon, L. Tessier, and M. C. Montel. 2005. Relationships between sensorial characteristics and microbial dynamics in "Registered Designation of Origin" Salers cheese. Int. Dairy J. 103:259-270.

Fuentes, M. C., S. Calsamiglia, C. Sánchez, A. González, J. R. Newbold, J. E. P. Santos, L. M. Rodriguez-Alcalá, and J. Fontecha. 2008. Effect of extruded linseed on productive and reproductive performance of lactating dairy cows. Livest. Sci. 113:144-154.

Jellema, A. 1991. Determination of free fatty acids in milk and milk products. Bull. Int. Dairy Fed., Brussels, Belgium.

Jones, E. L., K. J. Shingfield, C. Kohen, A. K. Jones, B. Lupoli, A. S. Grandison, D. E. Beever, C. M. Williams, P. C. Calder, and P. Yaqoob. 2005. Chemical, physical, and sensory properties of dairy products enriched with conjugated linoleic acid. J. Dairy Sci. 88:2923-2937.

Khanal, R. C., T. R. Dhiman, A. L. Ure, C. P. Brennand, R. L. Boman, and D. J. McMahon. 2005. Consumer acceptability of conjugated linoleic acid-enriched milk and Cheddar cheese from cows grazing on pasture. J. Dairy Sci. 88:1837-1847.

Kondojoyan, N., and J. L. Berdagué. 1996. A compilation of Relative Retention Indices for the Analysis of Aromatic Compounds. Edition du Laboratoire Flaveur, INRA de Theix, ClermontFerrand, France.

Kromhout, D., A. Menotti, H. Kestleloot, and S. Sans. 2002. Prevention of coronary heart disease by diet and lifestyle: Evidence from prospective cross-cultural, cohort, and interventional studies. Circulation 105:893-898.

Leffingwell, J. C. 2002, Chirality and Odour Perception. http://www. leffingwell.com/chirality/chirality.htm Accessed Jan. 21, 2009.

Leiber, F., M. Kreuzer, D. Nigg, H. R. Wettstein, and M. R. L. Scheeder. 2005. A study on the causes for the elevated n-3 fatty acids in cows' milk of alpine origin. Lipids 40:191-202.

McSweeney, P. L. H., and M. J. Sousa. 2000. Biochemical pathways for the production of flavour compounds in cheeses during ripening: A review. Lait 80:293-324.

NIST/EPA/NIH. 1996. Mass Spectral Database, version 1.5 PC. Standard Reference Database Program of the National Institute of Standards and Technology.

Parodi, P. W. 1997. Cow's milk fat components as potential anticarcinogenic agents. J. Nutr. 127:1055-1060.

Ryhanen, E. L., K. Tallavaara, J. M. Griinari, S. Jaakkola, S. MantereAlhonen, and K. J. Shingfield. 2005. Production of conjugated linoleic acid enriched milk and dairy products from cows receiving grass silage supplemented with a cereal-based concentrate containing rapeseed oil. Int. Dairy J. 15:207-217.

Shen, C., J. Xie, and X. Xu. 2007. The components of cuttlefish (Sepiella maindroni de Rochebruns) oil. Food Chem. 102:210214.

Tournayre, P., and J. L. Berdagué. 2005. Gas chromatographyolfaction analyses device and method. International Patent no. WO 2005/001470 A2.

Tournayre, P., and J. L. Berdagué, 2006. AcquiSniff ${ }^{\circledR}$ software: A tool for a complete analysis of GCO data. Registered trademark No. 023166185, May 28 2002, class 9 and 42 and APP reference: IDD. FR.001.210006.001R.P.2003.000.30000.

Verdier-Metz, I., B. Martin, P. Pradel, H. Albouy, M. C. Montel, and J. B. Coulon. 2005. Effect of grass-silage vs. hay diet on the characteristics of cheese: Interactions with the cheese model. Lait $85: 469-480$.

Wiley. 1995. Wiley 275K. 6th ed. Palisade Corp., Newfield, NY 